\title{
Validation and cultural adaptation of the Integrated Palliative care Outcome Scale (IPOS) for the Portuguese population
}

\author{
Bárbara Antunes ${ }^{1 *}$ (D) and Pedro Lopes Ferreira ${ }^{2,3}$
}

\begin{abstract}
Background: To culturally adapt and validate the Integrated Palliative care Outcome Scale to European Portuguese. Methods: Multi-centred observational study with 2 assessment points. Data were collected in nine centres using consecutive sampling. All patients were screened for eligibility. Inclusion criteria: $\geq 18$ years, mentally fit to give consent, diagnosed with an incurable, potentially life-threatening illness, read, write and understand Portuguese. Translation and back translation with independent native speakers blind to the original measure created a Portuguese version, which was culturally adapted using cognitive interviews. For psychometric testing, the COSMIN checklist was followed. Reliability and content validity were assessed for patient and staff versions. Construct and criterion validity were tested for patient version.

Results: 1703 individuals were screened between July 1st 2015 and February 2016, 135 (7.9\%) were included. Mean age was 66.8 years (SD 12.7), 58 (43\%) were female. Most patients (109; 80.7\%) had a cancer diagnosis. Cronbach's alpha showed good internal consistency, 0.657 for patient, 0.705 for staff versions. Intraclass correlation coefficient testing reproducibility revealed very good reliability, $0.794-0.950$ for patient and $0.456-0.925$ for staff versions. There was good content validity and significant results for construct validity. Physical symptoms were better detected by females. IPOS could discriminate: practical issues in different places of care, based on cancer diagnosis, physical and emotional symptoms based on life expectancy both for patient and professional dimensions, physical and emotional symptoms based on phase of illness, for professional dimensions, and physical symptoms from the patients' viewpoint.
\end{abstract}

Conclusions: The Portuguese IPOS is a reliable and valid measure.

Keywords: Patient-centred outcome measures, Palliative care, Outcome measurement, Palliative care outcome scale, Validation

\footnotetext{
* Correspondence: bc521@medschl.cam.ac.uk

'Primary Care Unit, Department of Public Health and Primary Care, University of Cambridge, Cambridge, UK

Full list of author information is available at the end of the article
}

(C) The Author(s). 2020 Open Access This article is licensed under a Creative Commons Attribution 4.0 International License, which permits use, sharing, adaptation, distribution and reproduction in any medium or format, as long as you give appropriate credit to the original author(s) and the source, provide a link to the Creative Commons licence, and indicate if changes were made. The images or other third party material in this article are included in the article's Creative Commons licence, unless indicated otherwise in a credit line to the material. If material is not included in the article's Creative Commons licence and your intended use is not permitted by statutory regulation or exceeds the permitted use, you will need to obtain permission directly from the copyright holder. To view a copy of this licence, visit http://creativecommons.org/licenses/by/4.0/ The Creative Commons Public Domain Dedication waiver (http://creativecommons.org/publicdomain/zero/1.0/) applies to the data made available in this article, unless otherwise stated in a credit line to the data. 


\section{Background}

The Integrated Palliative care Outcome Scale (IPOS) [1] is a patient-centred outcome measure resulting from the merge of two previously existing measures: the Palliative care Outcome Scale and the Palliative care Outcome Scale-Symptoms [2]. IPOS was developed at the request of several clinicians wanting a more user-friendly measure for clinical practice. Two versions were developed, one to be self-reported by patients, and a staff-proxy-reported to be filled by healthcare professionals, considering the perceptions and holistic assessment of the symptoms and other concerns the patient might have.

The aim of this study was twofold: (i) to translate, culturally adapt and validate the original English IPOS into Portuguese, and (ii) to compare the results obtained by the two versions of IPOS.

\section{Methods}

\section{Linguistic and cultural adaptation}

We followed the internationally defined methodology for the linguistic and cultural adaptation for the validation of outcome measures proposed by the COnsensus-based Standards for the selection of health Measurement INstruments (COSMIN) checklist [3] and the sequential approach for the translation [4].

After seeking and getting consent from the authors of the original IPOS measure, two independent bilingual native Portuguese speaking translators, one clinical and one non-clinical, both blind to the original English IPOS for patients, created two Portuguese versions. Next, two other native Portuguese speaking independent reviewers not blind to the original IPOS developed a consensus Portuguese version. This was then sent to two other independent native English-speaking translators, also blind to the original English IPOS, who back translated it into English. Comparing this back translated version with the original one, the same reviewers developed a second Portuguese consensus version.

Then, three clinical revisions were performed by one specialist palliative care doctor, one specialist palliative care nurse and one non-clinical researcher in palliative care - all native Portuguese. These experts were asked to look at both versions and comment for each question. Three possible outcomes might arise: (1) question was correctly written and no change was proposed, (2) question was incorrectly phrased and an alternative question was proposed; or (3) question was correctly written but an alternative would better. Based on the patient version, a final clinical review of the staff version of IPOS was also performed by the same experts.

Next, cognitive interviews were performed with 12 palliative care patients and nine healthcare professionals. Each patient had an individual interview and professionals were interviewed in two groups. The purpose of these interviews was to check acceptability by patients and staff, without ambiguity and redundancy and lack of important items. A final Portuguese version was obtained [5].

\section{Study design}

This was a multi-centred observational study with two assessment points. Data were collected in nine centres using consecutive sampling. All patients attending the participant services were screened for eligibility. Inclusion criteria were to be 18 years or older, mentally fit to give consent, diagnosed with an incurable, potentially life-threatening illness, read, write and understand Portuguese. Exclusion criteria included patients in distress or cognitively impaired. All professionals who provided care for participant patients were eligible for this study. They filled the staff proxy IPOS independently from the corresponding patients.

A standard operating procedures manual was previously developed and distributed to all centres in the person of the facilitator/champion leading the study locally.

After checking data quality, Little's MCAR test was implemented to verify if data were missing at random. We adopted the following criteria: rates $<1 \%$ are trivial, $1-5 \%$ are manageable, $5-15 \%$ require sophisticated statistical methods to handle, and $>15 \%$ may severely impact any form of interpretation [6].

Ethical approvals were granted in accordance with the 1964 Helsinki declaration and its later amendments or comparable ethical Standard be the following Ethics Committees: S. João Hospital (no reference number), Regional Health Authorities of Centro (reference 77/ 2015) and of Lisbon and Tagus Valley (reference 6801/ CES/2015), Vila Nova de Gaia/Espinho Hospital Centre (reference 275/2015), Lisbon Cancer Institute (reference UIC/967 n 89/2015), S. João de Deus Institute (reference CEISJD03_15); Lisbon Medicine Academic Centre (reference 51/15), and Nordeste Health Local Unit (no reference number). Informed written (signed) consent was obtained from all participants (patients and healthcare professionals). SPSSv22 software was used.

\section{Measures used}

IPOS [1], the measure under study, is a brief, 19-item, multidimensional scale designed to capture core concerns in palliative care. Item 1 is an open question regarding the three main problems or worries the patient/ professional had in the past week; items 2 to 9 are set on 5 -point Likert scales based on descriptors, item 2 lists ten of the most common physical symptoms in a palliative population, with the possibility of an additional three symptoms (not present in the list); item 3 is about anxiety, item 4 pertains to family/friends worries, item 5 asks about depression; item 6 is feeling at peace; item 7 addresses sharing feelings with significant people; item 8 
is about information needs and item 9 concerns practical problems related to their illness. In the patient version, there is an extra item asking if they had filled the questionnaire alone or with help. At the very end, there is a trigger in the form of a footnote noting that if the patient became worried about any of the issues raised by the questionnaire, they should/are advised to talk to their healthcare professional about those worries.

Each of the ten physical symptoms and all the following four emotional symptoms were linearly converted into a 0-100 scale, in which higher scores corresponded to higher severity symptoms. Additionally, items 7 to 9 were converted to a $0-100$ scale representing the functionality associated to each question. An average for each symptom and functionality item was accordingly computed.

The Portuguese EuroQol questionnaire (EQ-5D-3L) [7] allows quantifying two main components of health related quality of life: a first description of health status in the form of five dimensions or domains and a numeric value associated with the perceived global health status by the individual. These components are used in cost-utility economic evaluations, after transforming the descriptive system into a unique utility score. There are five items set in a 3-point Likert scale with descriptors. The items pertain to mobility, self-care, usual activities, pain/discomfort and anxiety/depression. It also has a numeric analogue visual scale (EQ-VAS) from 0 (the worst possible health state) to 100 (the best possible health state) so that the respondent can quantify their health state in the moment when filling the questionnaire. The authors of the Portuguese version state that this measure has good accessibility, reliability and validity in measuring health $[7,8]$. The obtained utility score ranges from 0 (death) to 1 (perfect health), allowing for negative values corresponding to health state perceived as worse than death.

The Portuguese translation of the European Organization for Research and Treatment of Cancer Quality of Life Questionnaire Core (EORTC QLQ-C30) $[9,10]$ is a 30item questionnaire, 24 items compose nine multi-item scales, namely, five functional subscales (physical, role, cognitive, emotional, and social); a global health/QoL subscale and three symptom subscales (fatigue, pain, and nausea/ vomiting). The remaining six items are single-item assessing symptoms commonly reported by cancer patients (dyspnoea, appetite loss, sleep disturbance, constipation, and diarrhoea) and one remaining item related to the perceived financial impact of cancer. All items are scored on 4-point Likert scale ranging from 1 (not at all) to 4 (very much), apart from two items of the global health/QoL subscale, which use a modified 7-anchor linear analogue scale. All scales range from 0 to 100 . A high score for functional scales and global health status/QoL represents a healthy level of functioning and QoL. For each subscale, a score between 0 and 7 is considered normal, between 8 and 10 mild, between 11 and 14 moderate and between 15 and 21 severe. The authors conclude that the Portuguese EORTC QLQ C-30 has good metric properties.

The Portuguese Hospital Anxiety and Depression Scale (HADS) [11] screens for anxiety and depression states and has 14 items divided into two subscales. These are based on a 4-point Likert scale, with descriptive answers, comprised of seven items each, scored separately. The authors propose a clinical cut-off of 11 for depression and anxiety. The authors conclude that the Portuguese HADS is reliable and valid to assess depression and anxiety in different medical settings and disease populations.

'Phase of illness' is a conceptualization of a patient's illness in five distinct, clinically meaningful phasesstable, unstable, deteriorating, terminal, bereavement (this last omitted in the present study) - developed in context of the Australian Case Mix Classification. It can be used as an indicator of acuity and reflects complexity within the disease trajectory $[12,13]$.

Demographic and clinical variables were also collected. The content in the open questions $1 \mathrm{a}, 1 \mathrm{~b}$ and $1 \mathrm{c}$ was aggregated to define the most prevalent worries occurring in the previous week of completion.

\section{Reliability}

Reliability was addressed by the intertemporal stability and the internal consistency. The intertemporal stability was tested in inpatients and outpatients with a guarantee of no clinical change, by intraclass correlation coefficient (ICC), on average, in a 1-week test-retest design. A score smaller that 0.5 is considered weak, between 0.5 and 0.75 moderate, between 0.75 and 0.9 good, and larger than 0.9 excellent [14]. The inter-rater reliability between staff members was also assessed.

Internal consistency was tested by the Cronbach's alpha coefficient, which should have scores between 0.7 and 0.9 [15]. However, following author's advice [1], we also lowered the lower limit 0.6 due to the multidimensionality and non-redundancy of IPOS [16].

The following two hypotheses were formulated:

$\mathrm{H}_{1}$ : The Portuguese version of the IPOS shows good intertemporal stability.

$\mathrm{H}_{2}$ : The Portuguese version of the IPOS shows good internal consistency.

\section{Validity}

Validity was addressed by the content, construct, and criterion validity $[15,16]$. The former has been tested through the clinical reviews and the cognitive debriefing interviews.

Construct validity was tested by hypotheses with known groups stratified by sociodemographic variables 
(age, gender, and education level) and some clinical variables (place of care, type of disease, life expectancy and phase of illness).

The following hypotheses were raised:

$\mathrm{H}_{3}$ : IPOS can discriminate based on the sociodemographic variable age.

$\mathrm{H}_{4}$ : IPOS can discriminate based on the sociodemographic variable gender.

$\mathrm{H}_{5}$ : IPOS can discriminate based on the sociodemographic variable education level. $\mathrm{H}_{6}$ : IPOS can discriminate based on the clinical variable place of care.

$\mathrm{H}_{7}$ : IPOS can discriminate based on the clinical variable type of disease.

$\mathrm{H}_{8}$ : IPOS can discriminate based on the clinical variable life expectancy.

$\mathrm{H}_{9}$ : IPOS can discriminate based on the clinical variable phase of illness.

Age and gender were not expected to influence IPOS scores. Less educated patients might have more symptoms with greater impact on quality of life. Same phenomenon was expected for unstable patients.

Normality tests were first performed. Two-sample independent $\mathrm{t}$-tests were applied when normality assumed; if not, chi-squared and Mann-Whitney $U$ tests were used.

$P$ values below 0.05 are considered statistically significant.

To test the criterion validity, we used bivariate statistical analyses (Pearson's $r$ correlation coefficients) between the dimensions of the Portuguese version of the IPOS and other measuring instruments, namely EQ-5D$3 \mathrm{~L}$ (index and VAS), EORTC QLQ-C30 (functional index, symptom scale, and quality of life) and HADS (anxiety and depression) items. We hypothesised that items measuring similar constructs would have higher correlations and items measuring different constructs would have a lower correlation. Correlations less than 0.3 , between 0.3 and 0.5 , and higher than 0.5 were defined as weak, moderate and strong, respectively [17].

The following three hypotheses were formulated:

$\mathrm{H}_{10}$ : IPOS dimensions are correlated with similar

EQ-5D-3L dimensions.

$\mathrm{H}_{11}$ : IPOS dimensions are correlated with similar EORTC QLQ-C30 dimensions.

$\mathrm{H}_{12}$ : IPOS dimensions are correlated with similar HADS dimensions.

We expect convergence between similar dimensions and divergence for distinct dimensions' scores.

\section{Results}

\section{Linguistic and cultural adaptation}

There were grammatical and content differences in the first translation stage, regarding items/questions phrasing as well as the response categories. There were differences in the backward translation, namely verb tenses and the use of synonyms, rather than the direct translation of words. Both issues were resolved by discussion with both reviewers.

The clinical revisions flagged differences in verb tenses in three items which were discussed, and changes were made to create the final version. In relation to the cognitive interviews to determine content (face) validity, these were conducted in two palliative care services in two major hospitals in the North of Portugal. Twelve patients were individually interviewed, and nine healthcare professionals were interviewed in two groups. See Supplemental Material Table 1 for demographics, time of completion and opinions on the IPOS from all respondents.

Main changes to finalise the Portuguese IPOS were: (i) to remove numerals indicative of the scores in the different items in each response square; (ii) to alter the questionnaire instructions of the healthcare professional to clarify that the last response option should be used for "not applicable" as well as "unknown"; (iii) to alter the instructions in the patient questionnaire to avoid repetition of requesting the respondent to choose the best answer and mark it with an " $\mathrm{x}$ " in the corresponding square; (iv) to add space between the groups of items in page 2 as well as add the time period to which the items pertain to, namely, "During the last week".

\section{Data collection}

Data were missing at random (Little's MCAR test showed Chi-Square $=2452.9 ; \quad p=0.213$ ). Missing data varied between 1 and $5 \%$, as expected in palliative populations, most questionnaire items presented a non-parametric distribution, so the imputation of the median was used to handle missing data.

\section{Demographic and clinical data}

1703 individuals were screened in nine centres of mainland Portugal between July 1st 2015 and 20th February 2016. Among them, 1410 (82.8\%) were immediately considered non eligible, mainly because they were not enrolled in palliative care, were less than 18 years of age, or could not read, write or understand Portuguese. We excluded 140 (8.2\%) more individuals mainly because they were excessively suffering, or they were cognitively deteriorated. There were 18 (1.1\%) eligible patients who declined participation.

A total of 135 (7.9\%) patients were included and filled the questionnaires without help, most $(98 ; 72.6 \%)$ were approached to participate in the study whilst in outpatient consultations. Table 1 presents demographic and clinical information for respondent patients.

Most patients were older male with low literacy, mainly diagnosed with cancer, receiving specialized palliative care, and in a stable phase of their illness. However, their mean quality of life index was low, they 
Table 1 Demographic and clinical information of participating patients

\begin{tabular}{|c|c|c|c|}
\hline \multirow[b]{2}{*}{ Variable } & \multirow[b]{2}{*}{ Value } & \multicolumn{2}{|l|}{ Patients } \\
\hline & & $\mathrm{N}$ & $\%$ \\
\hline \multirow[t]{2}{*}{ Gender } & Male & 77 & 57.0 \\
\hline & Female & 58 & 43.0 \\
\hline \multirow[t]{4}{*}{ Age (years) } & $<65$ & 57 & 42.2 \\
\hline & $65+$ & 78 & 57.8 \\
\hline & Min - Max & 29-94 & \\
\hline & Mean \pm standard deviation & $66.8 \pm 12.7$ & \\
\hline \multirow[t]{5}{*}{ Education } & Reads and writes & 5 & 3.7 \\
\hline & 4 years & 81 & 60.0 \\
\hline & 6 years & 20 & 14.8 \\
\hline & 9 years & 10 & 7.4 \\
\hline & 10 years to college & 19 & 14.0 \\
\hline \multirow[t]{3}{*}{ Geographical Region } & North & 74 & 54.8 \\
\hline & Centre & 25 & 18.5 \\
\hline & South & 36 & 26.7 \\
\hline \multirow[t]{3}{*}{ Area } & Urban & 94 & 69.6 \\
\hline & Peri-urban & 31 & 23.0 \\
\hline & Rural & 10 & 7.4 \\
\hline \multirow[t]{3}{*}{ Place of care } & Primary care & 28 & 20.7 \\
\hline & Hospital & 25 & 18.5 \\
\hline & Palliative care & 82 & 60.7 \\
\hline \multirow[t]{2}{*}{ Cancer diagnosis } & Yes & 109 & 80.7 \\
\hline & No & 26 & 19.3 \\
\hline \multirow[t]{3}{*}{ Life expectancy } & Less than 6 months & 48 & 35.6 \\
\hline & Between 6 months and 1 year & 47 & 34.8 \\
\hline & More than 1 year & 40 & 29.6 \\
\hline \multirow[t]{3}{*}{ Phase of illness } & Stable & 64 & 47.4 \\
\hline & Unstable & 28 & 20.7 \\
\hline & Deteriorating & 43 & 31.9 \\
\hline \multirow[t]{2}{*}{ Quality of Life } & Mean Index & 31.4 & \\
\hline & Mean VAS & 53.7 & \\
\hline \multirow[t]{5}{*}{ Anxiety (HADS) } & Normal (0-7) & 11 & 8.1 \\
\hline & Mild (8-10) & 16 & 11.9 \\
\hline & Moderate (11-14) & 66 & 48.9 \\
\hline & Severe $(15-21)$ & 42 & 31.1 \\
\hline & Mean \pm standard deviation & $12.7 \pm 3.1$ & \\
\hline \multirow[t]{5}{*}{ Depression (HADS) } & Normal (0-7) & 17 & 12.6 \\
\hline & Mild (8-10) & 63 & 46.7 \\
\hline & Moderate (11-14) & 48 & 35.6 \\
\hline & Severe (15-21) & 7 & 5.2 \\
\hline & Mean \pm standard deviation & $10.1 \pm 2.6$ & \\
\hline EORTC Quality of Life & & $49.7 \pm 20.6$ & \\
\hline \multirow[t]{2}{*}{ EORTC Functional scales } & Physical functioning & $48.4 \pm 28.7$ & \\
\hline & Role functioning & $51.5 \pm 34.7$ & \\
\hline
\end{tabular}


Table 1 Demographic and clinical information of participating patients (Continued)

\begin{tabular}{lll}
\hline & & Patients \\
\cline { 3 - 3 } Variable & Value & $\mathbf{N}$ \\
\hline & Emotional functioning & $62.5 \pm 24.2$ \\
EORTC Symptom scales & Cognitive functioning & $75.4 \pm 23.2$ \\
& Social functioning & $66.9 \pm 30.9$ \\
& Fatigue & $49.0 \pm 25.4$ \\
& Nausea and vomiting & $8.1 \pm 16.5$ \\
& Pain & $35.1 \pm 29.1$ \\
& Dyspnoea & $14.1 \pm 26.5$ \\
& Insomnia & $32.6 \pm 34.4$ \\
& Appetite loss & $30.9 \pm 36.6$ \\
& Constipation & $24.9 \pm 31.7$ \\
& Diarrhoea & $9.1 \pm 20.9$ \\
& Financial impact & $32.6 \pm 35.8$ \\
\hline
\end{tabular}

showed high scores of anxiety and low physical and emotional functioning scores. Their main reported symptoms were fatigue and pain.

In Table 2 we present the mean scores for each IPOS item when filled by patients and assigned by healthcare professionals. By comparing, for each patient, his/her score and the one provided by the healthcare professional, we also present the results from the paired samples t-test.
Emotional symptoms are more prevalent, especially those measuring family and patient anxiety, and depression. Regarding physical symptoms, the presence of weakness or lack of energy, pain, and poor mobility were the most prevalent. Vomiting, nausea and shortness of breath are the symptoms less present in these patients.

Comparing patients and professionals scores, we note lower scores among professionals regarding physical

Table 2 Descriptive statistics of IPOS items (\%) - $n=134$

\begin{tabular}{|c|c|c|c|c|}
\hline & & Patients & Staff & $|t|$ (Sig.) \\
\hline \multirow[t]{11}{*}{ Physical symptoms } & Pain & 42.0 & 35.9 & $1.914(p=0.058)$ \\
\hline & Shortness of breath & 15.0 & 14.8 & $0.118(p=0.906)$ \\
\hline & Lack of energy & 42.1 & 45.6 & $1.598(p=0.112)$ \\
\hline & Nausea & 12.6 & 11.3 & $0.733(p=0.465)$ \\
\hline & Feeling sick & 8.7 & 6.4 & $1.801(p=0.074)$ \\
\hline & Poor appetite & 34.5 & 30.4 & $1.374(p=0.172)$ \\
\hline & Constipated & 28.2 & 19.0 & $3.923(p<0.001)$ \\
\hline & Wounds in mouth or mouth dry & 31.4 & 10.6 & $7.450(\mathbf{p}<0.001)$ \\
\hline & Sleepiness & 33.1 & 14.7 & $7.493(p>0.001)$ \\
\hline & Lack of mobility & 39.2 & 41.4 & $1.029(p=0.305)$ \\
\hline & Total subscale score & 28.7 & 23.3 & $5.233(\mathbf{p}<\mathbf{0 . 0 0 1})$ \\
\hline \multirow[t]{5}{*}{ Emotional symptoms } & Anxiety & 56.9 & 54.5 & $0.921(p=0.359)$ \\
\hline & Family/friends worry & 70.3 & 62.4 & $2.693(p=0.008)$ \\
\hline & Depression & 47.3 & 42.0 & $2.103(p=0.037)$ \\
\hline & Feeling at peace & 35.8 & 45.0 & $3.151(p=0.002)$ \\
\hline & Total subscale score & 52.7 & 50.7 & $1.206(p=0.230)$ \\
\hline \multirow{4}{*}{$\begin{array}{l}\text { Communications/ } \\
\text { practical issues }\end{array}$} & Sharing feelings & 62.9 & 48.6 & $4.285(\mathbf{p}<\mathbf{0 . 0 0 1})$ \\
\hline & Info needs & 83.6 & 80.9 & $0.939(p=0.349)$ \\
\hline & Practical problems & 76.5 & 68.8 & $2.487(\boldsymbol{p}=\mathbf{0 . 0 1 5})$ \\
\hline & Total subscale score & 73.9 & 65.4 & $4.217(\mathbf{p}<\mathbf{0 . 0 0 1})$ \\
\hline
\end{tabular}

$\mathrm{P}$ values below 0.05 , considered statistically significant, are in bold letters 
symptoms as constipation, wounds in mouth or mouth dry, and trouble in sleep, as well as the emotional symptoms, being worried about family and friends, depressed, or feeling at peace. How patients' practical problems have been solved is also scored lower by healthcare professionals.

The input from the open question about the main concerns patients reported and those observed and reported by professionals are presented in Supplemental Material Table 2. Completion rates of all 3 items was higher in professionals than in patients. Regarding rate of completeness for each of the items, 1a had the highest (71\% for patients and $92 \%$ for professionals), item $1 \mathrm{~b}$ followed (36\% for patients and $64 \%$ for professionals) and finally, item 1c was the least responded to with $17 \%$ of patients completing it and $30 \%$ of professionals completing it. From the patient perspective, patients are more concerned with the disease itself and with their health status. Pain also occupies a relevant position, as does the concern about the impact of their health status in their family members. The concerns about their actual dependence, about their future and about death are also relevant for patients. Regarding the perspective of healthcare professionals, they much more recognise patients' concerns about the future, as well as about their disease and health status, and about treatments they will be submitted to.

\section{Reliability}

Table 3 shows the test-retest reliability scores for both patient and professionals' versions, as well as the internal consistency of the three main dimensions and the global score of IPOS.

IPOS items showed good test-retest reliability $\left(\mathrm{H}_{1}\right)$, with ICC from 0.794 (feeling sick) to 0.950 (poor appetite) for patients, and from 0.456 (family/friends worry) to 0.925 (shortness of breath) for professionals.

The Cronbach's $\alpha$ measuring the internal consistency is, in general, moderate to high $\left(\mathrm{H}_{2}\right)$ with scores of 0.657 for patients and 0.705 for healthcare professionals. All dimensions had also acceptable internal consistency, except for the dimension 'communication/practical issues' for patients that showed a very weak score.

\section{Validity}

Having the content validity assured by the interviews with experts (patients and professionals) during the cultural adaptation of both versions, we started by testing construct validity. We used some sociodemographic and clinical variables and studied the behaviour of the

Table 3 IPOS reliability for patients and professionals

\begin{tabular}{|c|c|c|c|c|c|}
\hline & & \multicolumn{2}{|c|}{ Patients } & \multicolumn{2}{|l|}{ Staff } \\
\hline & & ICC & Alpha & $\overline{I C C}$ & Alpha \\
\hline \multirow[t]{11}{*}{ Physical symptoms } & & & 0.725 & & 0.660 \\
\hline & Pain & 0.884 & & 0.862 & \\
\hline & Shortness of breath & 0.810 & & 0.925 & \\
\hline & Lack of energy & 0.851 & & 0.713 & \\
\hline & Nausea & 0.812 & & 0.759 & \\
\hline & Feeling sick & 0.794 & & 0.644 & \\
\hline & Poor appetite & 0.950 & & 0.821 & \\
\hline & Constipated & 0.938 & & 0.706 & \\
\hline & Wounds in mouth or mouth dry & 0.895 & & 0.696 & \\
\hline & Sleepiness & 0.882 & & 0.632 & \\
\hline & Lack of mobility & 0.887 & & 0.852 & \\
\hline \multirow[t]{5}{*}{ Emotional symptoms } & & & 0.615 & & 0.658 \\
\hline & Anxiety & 0.909 & & 0.525 & \\
\hline & Family/friends worry & 0.871 & & 0.456 & \\
\hline & Depression & 0.899 & & 0.625 & \\
\hline & Feeling at peace & 0.894 & & 0.453 & \\
\hline \multirow{4}{*}{$\begin{array}{l}\text { Communications/ } \\
\text { practical issues }\end{array}$} & & & 0.223 & & 0.617 \\
\hline & Sharing feelings & 0.810 & & 0.514 & \\
\hline & Info needs & 0.860 & & 0.720 & \\
\hline & Practical problems & 0.938 & & 0.598 & \\
\hline All dimensions & All items & & 0.657 & & 0.705 \\
\hline
\end{tabular}




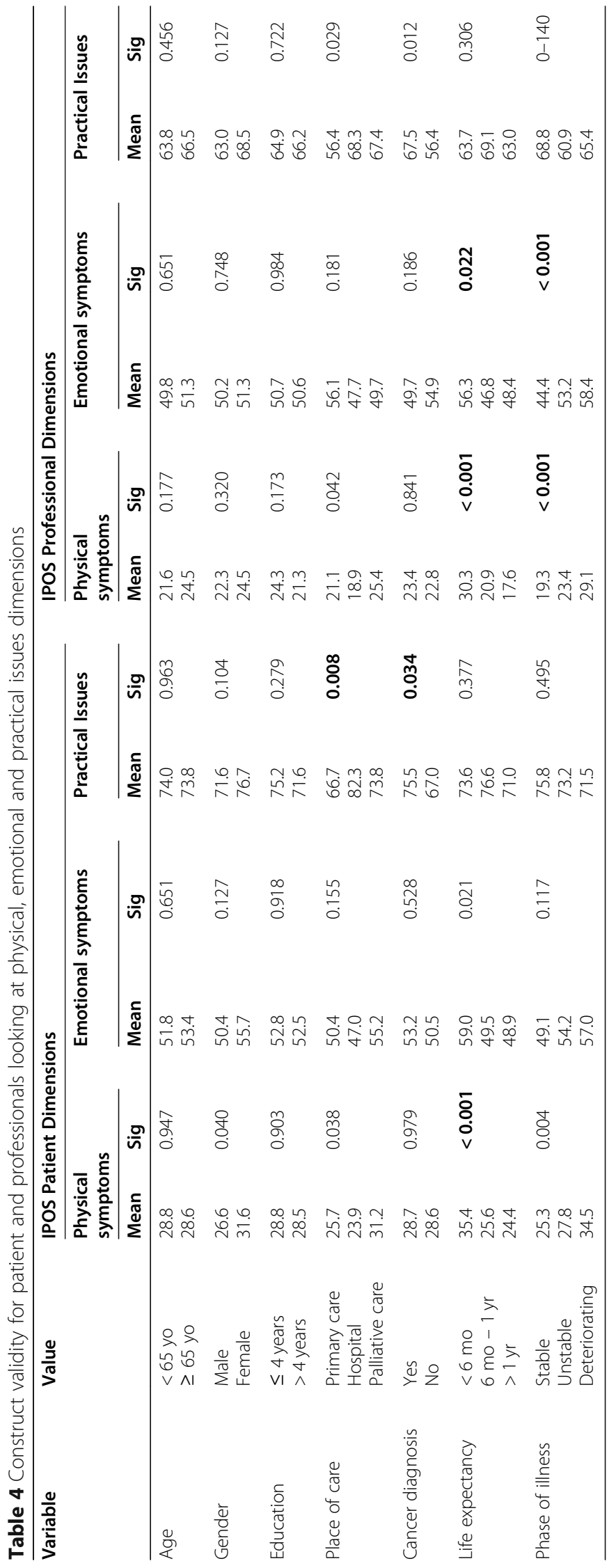


different IPOS dimensions for different levels of those variables, regarding the patient version, for which the mean scores are presented in Table 4.

Of the three sociodemographic variables studied, IPOS could only discriminate emotional symptoms based on gender $\left(\mathrm{H}_{3}\right)$. Females showed more physical symptoms than male patients did. Regarding clinical variables, communication and practical issues have different significant scores regarding the various places of care $\left(\mathrm{H}_{6}\right)$, meaning that higher scores correspond to inpatients and lower scores to primary care. IPOS could discriminate practical issues, based on cancer diagnosis $\left(\mathrm{H}_{7}\right)$, physical and emotional symptoms based on life expectancy $\left(\mathrm{H}_{8}\right)$ both for patient and professional dimensions. IPOS could discriminate physical and emotional symptoms based on phase of illness $\left(\mathrm{H}_{9}\right)$, for professional dimensions, and physical symptoms from patients' viewpoint. In summary, cancer patients showed more easiness in solving practical issues, patients with less than 6 months of life expectancy reported higher physical and emotional symptoms and were equally perceived as such by staff, and these were able to better recognise physical and emotional symptoms among those patients who were in a more deteriorating phase of their illness.

Regarding criterion validity, Table 5 shows there were good correlations between EQ-5D-3L index and IPOS physical and emotional symptoms and a good correlation between EQ-VAS and all IPOS dimensions. This measure correlates poorly with practical issues $\left(\mathrm{H}_{10}\right)$.

In relation to the EORTC $\left(\mathrm{H}_{11}\right)$ the functional index showed significant correlations with both IPOS physical and emotional symptoms, the symptoms scale correlated stronger with physical and emotional symptoms and moderately with practical issues, and the quality of life measure correlated significantly with physical symptoms and with emotional symptoms.

Finally, the HADS $\left(\mathrm{H}_{12}\right)$ correlated poorly with physical symptoms and significantly with emotional symptoms. The anxiety indicator also correlated significantly with IPOS practical issues.

\section{Discussion}

The Portuguese IPOS is a reliable and valid measure, appropriate to use with patients with advanced, incurable illnesses. Regarding the translation process and cultural adaptation there were, as expected, adjustments made to the direct translation of some concepts and in the overall appearance of the measure. These changes are well aligned with the literature, mainly with the French [18] and Swedish [19] translations and cultural adaptions of this measure. Regarding the open question items $1 \mathrm{a}, 1 \mathrm{~b}$ and $1 \mathrm{c}$, these gave insights to some of the issues worrying patients, which was important and informative for healthcare professionals to act upon in real time. This item could also provide a good starter for the clinical appointment.

Regarding psychometric properties, there was good agreement between patient and professional ratings, especially in most physical symptoms. It is expected that some proxy ratings are lower for professionals and higher when done by proxy family ratings and indeed, there were lower proxy ratings for some items. This measure also discriminates well between life expectancy (surprise question) and phase of illness. IPOS is comparable with other measures in the field, as it showed moderate correlations with the EORTC-QLQ-C30, the HADS and the EQ-5D-3L.

These results show commonalities with validity of the original English and German IPOS versions [1] and the Japanese version [20]. Indeed, the original measures showed similar results for most psychometric properties and it is noted that the moderate correlations are expected given that IPOS measures how a person is affected by their symptoms rather than the severity of symptoms.

\section{Strengths and limitations}

This was a multicentre study in different regions of the country and in different settings within all three sectors of the Portuguese healthcare system, thus securing good heterogeneity of our sample. As expected, in the specialised palliative care services, we observed a higher number of patients with a life expectancy under 6 months, 42

Table 5 Criterion validity (Correlations)

\begin{tabular}{llllr}
\hline Measure & Indicator & $\begin{array}{l}\text { Physical } \\
\text { symptoms }\end{array}$ & Emotional symptoms & Practical Issues \\
\hline EQ-5D-3L & Index & $-0.529(p<0.001)$ & $-0.395(p<0.001)$ & $0.028(p=0.748)$ \\
& EQ-VAS & $-0.309(p<0.001)$ & $-0.356(p<0.001)$ & $0.221(p=0.010)$ \\
EORTC & Functional index & $-0.532(p<0.001)$ & $-0.500(p<0.001)$ & $0.156(p=0.071)$ \\
& Symptoms scale & $0.659(p<0.001)$ & $0.371(p<0.001)$ & $-0.220(p=0.010)$ \\
& Quality of Life & $-0.399(p<0.001)$ & $-0.358(p<0.001)$ & $0.020(p=0.822)$ \\
HADS & Anxiety & $-0.155(p=0.072)$ & $-0.443(p<0.001)$ & $0.243(p=0.005)$ \\
& Depression & $0.226(p=0.008)$ & $0.308(p<0.001)$ & $-0.088(p=0.312)$ \\
\hline
\end{tabular}


(52.5\%), and in the health primary care services most patients were expected to live over one year, 20 (80\%). This shows that patients with palliative needs are present in all settings in all sectors of the healthcare system and that the IPOS is good to identify those needs in patients with advanced disease. However, there are limitations, namely, most participants were outpatients, so there is less representation of more ill patients; also, it would have been interesting to capture functional status and non-cancer diagnoses, to better understand our sample.

\section{Conclusions}

The Portuguese IPOS is a reliable and valid measure which can be used to identify palliative needs in people with advanced diseases, whether used by the patient or by a healthcare professional (proxy). Given the potential uses of patient centred outcome measures in clinical settings and healthcare system levels (micro, meso and macro), the Portuguese IPOS is an invaluable tool to be used in clinical practice and in research.

\section{Supplementary Information}

The online version contains supplementary material available at https://doi. org/10.1186/s12904-020-00685-z.

Additional file 1: Table 1. Demographics, time of completion and main opinions about IPOS by patients and healthcare professionals. Table 2. Open question 1a, 1b, 1c: "What have been the main concerns in the past week?"

\section{Abbreviations}

IPOS: Integrated Palliative care Outcome Scale; COSMIN: COnsensus-based Standards for the selection of health Measurement INstruments; EQ-5D3L: Portuguese EuroQol questionnaire; EQ-VAS: numeric analogue visual scale; EORTC QLQ-C30: European Organization for Research and Treatment of Cancer Quality of Life Questionnaire Core; HADS: Hospital Anxiety and Depression Scale; ICC: intraclass correlation coefficient

\section{Acknowledgements}

To all patients who contributed for data collection our most profound appreciation. Without them this work would not have been possible. Thank you to all healthcare professionals and care teams who performed data collection: Palliative care service of S. João de Deus de Montemor-o-Novo Hospital; Oncology service of CHVNG/E Hospital, Moreira Pinto, Enrique Dias, Ana Joaquim, Teresa Sarmento, Sandra Custódio; Palliative care teal (EIHSCP) of CHVNGaia/Espinho, EPE hospital; home palliative care team od IPOLFG hospital and palliative care team of IPOLFG, EPE hospital; palliative care service of São João, E.P.E. hospital, Cátia Coelho; palliative care team of Unidade Local de Saúde do Nordeste, Duarte Soares, Sara Fernandes, Silvia Asseiro; healthcare centre São Julião - Figueira da Foz, Sara Marques Baptista, Sandra Amaral, Pedro Figueiredo, Ana Castro; healthcare centre AlphaMouro and palliaitive care unit of Lisboa Norte, EPE hospital.

\section{Authors' contributions}

BA performed study procedures and collection of data, BA and PLF performed analysis of data and were responsible for drafting and editing of the manuscript. Both authors approved the final manuscript.

\section{Funding}

This study was funded by Calouste Gulbenkian Foundation - Programa Gulbenkian Inovar em Saúde. Bárbara Antunes was funded by Foundation for Science and Technology (FCT) - Grant number PD/BD/113664/2015,
Faculty of Medicine, University of Porto. The Doctoral Program Clinical and Health Services Research was funded by FCT - Grant number PD/0003/2013. Currently Bárbara Antunes is funded by the National Institute for Health Research (NIHR) Applied Research Collaboration East of England (ARC EoE) programme. The views expressed are those of the author(s) and not necessarily those of the NHS, the NIHR or the Department of Health and Social Care. The funding organizations had no role in the design of the study, collection, analysis, interpretation of the data, or writing of the manuscript.

\section{Availability of data and materials}

The datasets generated and/or analysed during the current study are available from the corresponding author on reasonable request.

\section{Ethics approval and consent to participate}

Ethical approval was granted from all Research Ethics Committees' included centres and was in accordance with the 1964 Helsinki declaration and its later amendments or comparable ethical Standard: Comissão de Ética para a Saúde do Centro Hospitalar de S. João - Entidade Pública Empresarial (no reference number); Comissão de Ética para a Saúde Administração Regional de Saúde Centro - 77/2015; Comissão de Ética para a Saúde de Lisboa e Vale do Tejo - 6801/CES/2015; Comissão de Ética do Centro Hospitalar de Vila Nova de Gaia/Espinho - 275/2015; Conselho de Investigação e da Comissão de Ética do Instituto Português de Oncologia de Lisboa Francisco Gentil, Entidade Pública Empresarial - UIC/967 n 89/2015; Comissão de Ética Instituto S. João de Deus - CEISJD03_15; Comissão de Ética do Centro Académico de Medicina de Lisboa - 51/15; Comissão de Ética da Unidade Local de Saúde do Nordeste Entidade Pública Empresarial - p, CE. Informed written (signed) consent was obtained from all participants (patients and healthcare professionals).

\section{Consent for publication}

Not applicable.

\section{Competing interests}

The authors declare that they have no competing interests.

\section{Author details}

${ }^{1}$ Primary Care Unit, Department of Public Health and Primary Care, University of Cambridge, Cambridge, UK. ${ }^{2}$ Centre for Health Studies and Research, University of Coimbra, Coimbra, Portugal. ${ }^{3}$ Faculty of Economics, University of Coimbra, Coimbra, Portugal.

Received: 26 June 2020 Accepted: 15 November 2020 Published online: 24 November 2020

\section{References}

1. Murtagh FE, Ramsenthaler C, Firth A, Groeneveld El, Lovell N, Simon ST, et al. A brief, patient- and proxy-reported outcome measure in advanced illness: Validity, reliability and responsiveness of the Integrated Palliative care Outcome Scale (IPOS). Palliat Med. 2019;33(8):1045-57.

2. Hearn J, Higginson IJ. Development and validation of a core outcome scale measure for palliative care: the palliative care. Qual Health Care. 1999;8: $219 \mathrm{e} 227$.

3. Mokkink LB, Terwee CB, Patrick DL, Alonson J, Stratford PW, Knol DL, et al. The COSMIN checklist for assessing the methodological quality of studies on measurement properties of health status measurement instruments: an international Delphi study. Qual Life Res. 2010;19:539-49. https://doi.org/10. 1007/s11136-010-9606-8.

4. Acquadro C, Conway K, Hareendran A, Aaronson N, European Regulatory Issues and Quality of Life Assessment (ERIQA) Group. Literature review of methods to translate health-related quality of life questionnaires for use in multinational clinical trials. Value Health. 2008;11(3):509-21.

5. POS Development Team. Manual for validation and cross-cultural adaptation of the Palliative Care Outcome Scale. A resource for palliative care. Available at: pos-pal.org. Accessed June 10, 2019.

6. Acuñna $E$, Rodriguez $C$. The treatment of missing values and its effect on classifier accuracy. In: Banks D, House L, FR MM, Arabie P, Gaul W, editors. Classification, Clustering and Data Mining Applications. Berlin: Springer; 2004. p. 639e648. 
7. Ferreira $L N$, Ferreira PL, Pereira LN, Oppe $M$. The valuation of the EQ-5D in Portugal. Qual Life Res. 2014;23(2):413-23.

8. Ferreira LN, Ferreira PL, Pereira LN, Oppe M. EQ-5D Portuguese population norms. Qual Life Res. 2014:23(2):425-30.

9. Ferreira PL. The Portuguese version of the EORTC QLQ-C30. Eur I Gynaecol Oncol. 1997;18(4):324.

10. Pais-Ribeiro J, Pinto C, Santos C. Validation study of the portuguese version of the QLC-C30-V.3. Psic. Saúde Doenças. 2008;9(1):89-102.

11. Pais-Ribeiro J, Silva I, Ferreira T, Martins A, Meneses R, Baltar M. Validation study of a Portuguese version of the hospital anxiety and depression scale. Psychol Health Med. 2006;12:2,225-37. https://doi.org/10.1080/ 13548500500524088

12. Eagar K, Watters P, Currow DC, et al. The Australian palliative care outcomes collaboration (PCOC) measuring the quality and outcomes of palliative care on a routine basis. Aust Health Rev. 2010:34:186-92.

13. Masso M, Allingham SF, Banfield M, et al. Palliative care phase: inter-rater reliability and acceptability in a national study. Palliat Med. 2015;29:22-30.

14. Koo TK, Li MY. A guideline of selecting and reporting intraclass correlation coefficients for reliability research. J Chiropr Med. 2016;15(2):155-63.

15. Terwee CB, Bot SD, de Boer MR, van der Windt DAWM, Knol DL, Dekker LM, et al. Quality criteria were proposed for measurement properties of health status questionnaires. J Clin Epidemiol. 2007:60(1):34-42.

16. de Vet HC, Terwee CB, Mokkink LB, Knol DL. Measurement in medicine. Cambridge: Cambridge University Press; 2011.

17. Cohen J. Statistical power analysis for the behavioural sciences. New York: Lawrence Erlbaum Associates; 1988

18. Sterie A, Bernard M. Challenges in a six-phase process of questionnaire adaptation: findings from the French translation of the Integrated Palliative care Outcome Scale. BMC Palliat Care. 2019;18:38. https://doi.org/10.1186/ s12904-019-0422-9.

19. Beck I, Möller UO, Malmström M, Klarare A, Samuelsson H, Hagelin CL, et al. Translation and cultural adaptation of the Integrated Palliative care Outcome Scale including cognitive interviewing with patients and staff. Palliative Care. 2017;16:49.

20. Sakurai H, Miyashita M, Imai K, Miyamoto S, Otani H, Oishi A, et al. Validation of the Integrated Palliative care Outcome Scale (IPOS) - Japanese version. Jpn J Clin Oncol. 2019:1-6. https://doi.org/10.1093/jijco/hyy203.

\section{Publisher's Note}

Springer Nature remains neutral with regard to jurisdictional claims in published maps and institutional affiliations.

Ready to submit your research? Choose BMC and benefit from:

- fast, convenient online submission

- thorough peer review by experienced researchers in your field

- rapid publication on acceptance

- support for research data, including large and complex data types

- gold Open Access which fosters wider collaboration and increased citations

- maximum visibility for your research: over $100 \mathrm{M}$ website views per year

At $\mathrm{BMC}$, research is always in progress.

Learn more biomedcentral.com/submissions 